\title{
EVOLVING TO COMPETENCE BASED SOCIAL WORK TRAINING
}

\author{
GUIDO CUYVERS \\ Social Work Department. K.H. Kempen University College. Geel, Belgium.
}

\begin{abstract}

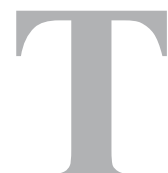

here is new paradigm in higher education which could be described as competence based education. In this article, we explore the conditions in which this paradigm can lead to better results of the educational process. We first define the meaning of 'competences' and we then describe how they were developed in the Flemish context. We also explain our competence framework, the real basis for competence based education. Next we focus on the consequences of this approach and finally we describe a way to implement this approach in an educational organization. For this article, we rely on the findings and the insights we developed in a research project realized in co-operation with partners of our university association (Minne, 2008).
\end{abstract}

Key words: competence based education, social work, educational process.

\section{RESUMEN}

\section{EVOLUCIONANDO HACIA LA FORMACIÓN DE TRABAJO SOCIAL BASADA EN LAS COMPETENCIAS}

Actualmente, existe un nuevo paradigma en la educación superior que podría describirse como la educación basada en las competencias. En el presente artículo, exploramos las condiciones en las que este paradigma podría conducirnos hacia una mejora de los resultados en el proceso educativo. En primer lugar, definimos el significado de 'competencias' para, después, describir cómo se desarrollaban en el contexto flamenco. También explicamos nuestro marco de competencias, la verdadera base para conseguir una educación basada en las competencias. A continuación, nos centramos en las consecuencias de este enfoque $\mathrm{y}$, finalmente, describimos la forma de implementarlo en un centro educativo. Para este artículo, contamos con los resultados y conocimientos obtenidos gracias a un proyecto de investigación realizado en colaboración con algunos compañeros de nuestra asociación universitaria (Minne, 2008).

Palabras clave: educación basada en las competencias, trabajo social, proceso educativo. 


\section{COMPETENCES}

In this article, we define competence as 'the whole of knowledge, insights, skills and attitudes which a professional uses in diverse professional situations to act in a wellconsidered and critical way'. As a consequence competent professionals have:

- domain specific knowledge;

- cognitive strategies;

- skills that are necessary to act professionally;

- meta cognition: this means insight in their own functioning, a kind of self regulation;

- affective components such as attitude, motivation, identification.

We must warn for a too narrow interpretation of competences; some reduce it to skills, implying that competence based education has a limited theoretical basis.

\subsection{Legislation on the Flemish-Dutch Accreditation stipulates that higher education institutes should describe their learning outcomes in terms of competences}

The Flemish and Dutch government imposed a frame of reference for the assessment and accreditation of all higher education institutes. One of the topics in this frame of reference concerns the objectives of study programmes. The institute has to demonstrate that the level and the orientation of their study programmes are guaranteed by the objectives. They have to be based on students mastering the general competences, general professional competences and specific professional competences. Moreover, the framework requires that a domain specific framework with the typical competences of that profession has been developed.

\subsection{Baobap}

The Flemish institutes that provide social work degree programmes gathered to develop a framework of competences together, so that they could all work with common insight in and a common list of competences to give social work a recognizable face in society. The starting point for this frame of reference is the international definition of social work (IFSW, 2000). Next they defined the fundamental core of social work in this way:

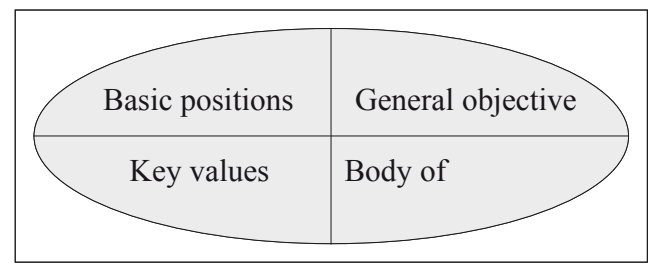

FIGURE 1: The core of social work

- The general objective of social work: social change, problem solving in human relationships, empowerment and liberation.

- The body of knowledge: this is knowledge of the professional field of social work, from which the practitioner learns theoretical and practical knowledge, insights and methodological knowledge. This contains knowledge of the human sciences and knowledge of the target groups.

- Basic positions of the social worker: this position is between man and society; they build bridges;

- The key values: norms, values, principles and how they are translated into legal rules. 
Around this core the Flemish social work institutes list five clusters of competences:

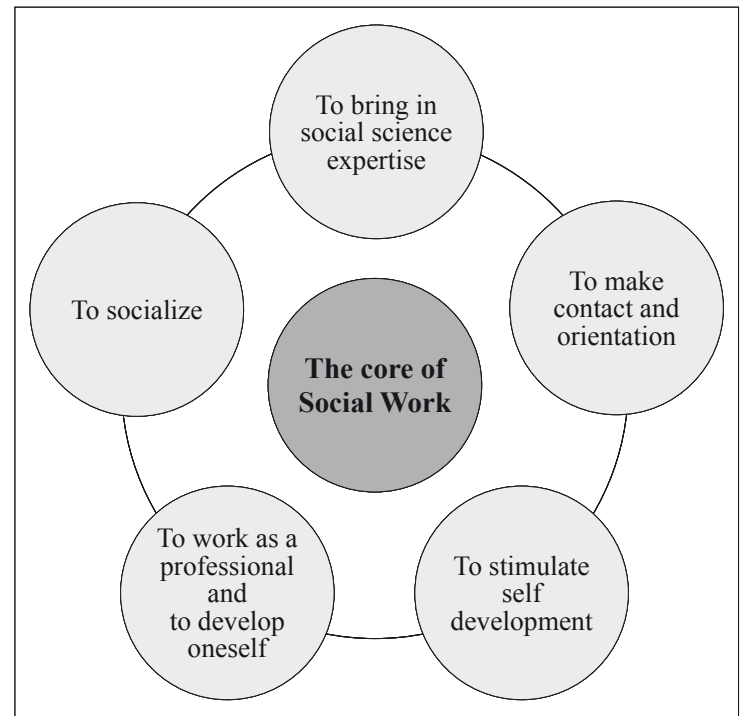

FIGURE 2: The clusters of competences

- To make contact and orientation.

- To make authentic contact in a professional relation.

- Consults a broad range of sources to estimate the situation together with the stakeholder.

- To stimulate self-development.

- Stimulates and supports the stakeholders in exploring, recognizing and coping with their needs, talents and expectations.

- Guides the stakeholders in a professional way to relevant arrangements and institutions.

- To bring in social science expertise.

- Uses adequate forms of communication and interaction, adapted to the stakeholders and to the kind of social processes.

- Designs and coaches social processes in consideration with the stakeholders and adapted to their situations.

- Acts with methodological expertise.

- To socialize.

- Points out tensions between the developing society and the stakeholders.

- Supports the stakeholders to relate to society and vice versa.

- Builds up partnerships to create inclusive co-existence with respect to ecological boundaries.

- To work as a professional and to develop oneself.

- Works together in a team and participates to achieve goals, works on the policy and management of the organization.

- Works in a multidisciplinary manner and within networks of organizations.

- Develops their own professionalization and contributes to exchanging experiences and to practice based research. 
A novice social worker must be able to handle this whole of competences in a well balanced way. This is a very important criterion in the evaluation of the Flemish Dutch Accreditation Organization. The institutes of higher education have to provide evidence that their graduates master all these competences.

The various institutes can tailor this competence list to their own specific educational views or objectives, but the core must be recognizable.

\subsection{Our application}

As every other institute in Flanders, we also developed a competence list. We briefly list the competences below.

$\mathrm{C} 1$. The social worker can relate authentically to people and groups of people within their function.

$\mathrm{C} 2$. The social worker can put interactions between people in context and describe them from a generalist perspective.

C3. The social worker can act socially and use their general knowledge of social sciences as well as their insights in practical cases.

C4. The social worker integrates ethics in their actions.

C5. The social worker operates from a critical reflection on the interactions between their own job, their professional field and society.

C6. The social worker can work in teams and in organisations and associate with partners in a network of organisations.

C7. The social worker evolves professionally in the perspective of life long learning.

C8. The social worker contributes to the identity and the development of the profession and to the recorded practice in the professional field.

C9. The social worker can guide people through the services and advice in matters of rights and duties.

We give one example of how a competence can be further elaborated.

\begin{tabular}{|c|c|c|}
\hline $\begin{array}{l}\text { PROFESSIONAL } \\
\text { COMPETENCIES }\end{array}$ & REALISATION & PROFICIENCY CRITERIA \\
\hline \multirow{3}{*}{$\begin{array}{l}\text { C1 } \\
\text { The social } \\
\text { worker } \\
\text { can relate } \\
\text { authentically } \\
\text { to people } \\
\text { and groups } \\
\text { of people } \\
\text { within their } \\
\text { function. }\end{array}$} & $\begin{array}{l}\text { C1.1 } \\
\text { The social worker } \\
\text { consciously } \\
\text { considers } \\
\text { interpersonal } \\
\text { processes. }\end{array}$ & $\begin{array}{l}\text { - The social worker can observe and make sense of inter- and } \\
\text { intrapersonal processes and relate them to each other. } \\
\text { - The social worker can recognise and describe dynamics, patterns } \\
\text { and projections in human interactions. } \\
\text { - The social worker reflects on their observations and can interpret } \\
\text { human interactions and can act accordingly. } \\
\text { - The social worker can direct a relationship functionally and } \\
\text { establish authentic contacts. }\end{array}$ \\
\hline & $\begin{array}{l}\text { C1.2 } \\
\text { The social worker } \\
\text { can deal with } \\
\text { cultural and sub } \\
\text { cultural differences. }\end{array}$ & $\begin{array}{l}\text { - The social worker has insight in the lives of different } \\
\text { communities. } \\
\text { - The social worker adopts their intercultural skills appropriately } \\
\text { when they relate to different communities. } \\
\text { - The social worker communicates differently depending on 1) } \\
\text { the needs of the people they work with and 2) on their way of } \\
\text { communicating. At the same time they remain authentic. }\end{array}$ \\
\hline & $\begin{array}{l}\text { C1.3 } \\
\text { The social worker } \\
\text { communicates } \\
\text { openly and clearly. }\end{array}$ & $\begin{array}{l}\text { - The social worker communicates spontaneously but selectively } \\
\text { about their inner processes. } \\
\text { - The social worker searches for feedback with other people and } \\
\text { knows how to value this feedback. }\end{array}$ \\
\hline
\end{tabular}




\begin{tabular}{|c|c|c|}
\hline $\begin{array}{l}\text { PROFESSIONAL } \\
\text { COMPETENCIES }\end{array}$ & REALISATION & PROFICIENCY CRITERIA \\
\hline \multirow{2}{*}{$\begin{array}{l}\text { C1 } \\
\text { The social } \\
\text { worker } \\
\text { can relate } \\
\text { authentically } \\
\text { to people } \\
\text { and groups } \\
\text { of people } \\
\text { within their } \\
\text { function. }\end{array}$} & $\begin{array}{l}\text { C1.4 Social worker } \\
\text { can give space to } \\
\text { others and take up } \\
\text { space themself. }\end{array}$ & $\begin{array}{l}\text { - The social worker keeps an eye to others and sees to it that they } \\
\text { can demonstrate themself and exert power. } \\
\text { - The social worker is visibly available for others and exerts } \\
\text { power. }\end{array}$ \\
\hline & $\begin{array}{l}\text { C1.5 } \\
\text { The social worker } \\
\text { can instigate other } \\
\text { people and can be } \\
\text { instigated by others. }\end{array}$ & $\begin{array}{l}\text { - The social worker can create confidence and trust with people. } \\
\text { - The social worker can motivate and support people when they go } \\
\text { through change. } \\
\text { - The social worker relates to people and shows real commitment in } \\
\text { his bonds with people. }\end{array}$ \\
\hline
\end{tabular}

FIGURE 3: Elaboration of a competence

\subsection{The difference between competence based and traditional education}

We consider competence based education as a new paradigm in higher education. It results from a changing society and changing demands from the professional field. It is useful to compare this new type of education with the traditional one. Competence based education is linked to the constructivist approach. This approach considers learning as an active process that is cumulative, self regulating, constructive and linked to contexts.

\begin{tabular}{|l|l|}
\hline TRADITIONAL EDUCATION & COMPETENCE BASED EDUCATION \\
$\begin{array}{l}\text { Knowledge, contents and discipline centred } \\
\text { skills as the basis of the curriculum }\end{array}$ & $\begin{array}{l}\text { Competences with tasks and situations from the } \\
\text { professional field as the basis of the curriculum } \\
\text { Students study predefined contents }\end{array}$ \\
$\begin{array}{l}\text { Students go through the same curriculum } \\
\text { path }\end{array}$ & $\begin{array}{l}\text { Depending on prior experiences and their entrance levels } \\
\text { the students have a personalized curriculum } \\
\text { Knowledge and skills are assessed } \\
\text { Teacher centred assessment } \\
\begin{array}{l}\text { Courses are derived from independent } \\
\text { disciplines }\end{array}\end{array}$ \\
$\begin{array}{l}\text { Learning path dependent } \\
\text { Includes self assessment and peer assessment } \\
\text { Exams as a final point }\end{array}$ & $\begin{array}{l}\text { Learning units are interdisciplinary as much as possible } \\
\text { Learning path independent } \\
\text { Assessment can also be the starting point for the design } \\
\text { of flexible learning paths } \\
\text { Assessment is also a kind of coaching } \\
\text { Assessment is a didactical instrument }\end{array}$ \\
$\begin{array}{l}\text { Subject matter based } \\
\text { The teaching process is central }\end{array}$ \\
\hline
\end{tabular}

FIGURE 4: Comparison traditional versus competence based education

\section{A FRAMEWORK}

So far we have only described the formal and legal framework which we have to work with in Flanders. Even more important is the development and the implementation of such a framework in the day-to-day running of a degree programme. It is a hard job that takes time and needs a lot of motivation and organizational measures.

If you change a degree programme in the direction of competence based education, you are faced with a real paradigm shift. Introducing a competence based approach is not a technical matter but a process of organizational change, of which the success is not guaranteed beforehand. It is not only a matter of changing the educational processes or contents of courses, it also means actually changing the organization. A successful implementation needs the recognition of eight components, four concerning the educational process, four concerning the organizational context. 
- The educational process:

- A competence based educational profile.

- A competence based educational vision.

- A competence based curriculum.

- Competence based courses and activities.

- The organizational context:

- Professional relationships with the professional field.

- A competence based personnel policy.

- An organization that supports competence based education.

- The coaching of the students.

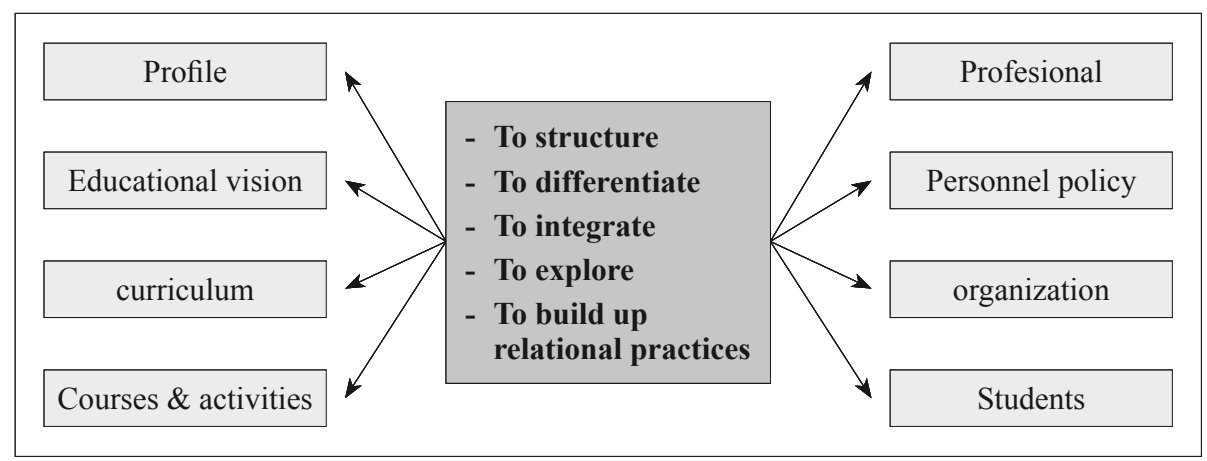

FIGURE 5: The components of competence based education

The development of competence based education is a complex and time consuming, but very promising process. We learned that you cannot successfully change a degree programme in that direction on the basis of co-incidence, or by trial-and-error. On the contrary, we detected five factors that are always present when attempts to develop competence based education were successful. Those factors are: to structure, to integrate, to differentiate, to explore and to build up relational practices.

- To structure:

To structure means to offer models or 'hat racks' to the students in their degree programme. A kind of structure is necessary for learning: to draw lines, to demonstrate the boundaries of the working area. That structuring offers certainty.

- To integrate:

To integrate means to look for relationships, to bring things together in a greater unity. People are often too analytical, so that after the analysis they forget to come back to synthesis or to show the coherence of the parts within the whole entity. A good example of integration is relating theory and practice.

- To explore:

To explore refers to the process of inquiry. It is the challenge to search for new things. Searching for change, for improvement, for innovation. To explore also refers to the tendency to learn, to develop, to grow. It also means to search for new things, to think outside paths already known. The ability to explore needs openness, appreciation and surprise.

- To build up relational practices:

Building up relational practices has to do with relationships between people, with authentic contact between people. Relational practices start to develop when people 
are interested in each other with respect and appreciation. It is a special way of cooperation: co-operation starting from an appreciative attitude.

\subsection{A competence based educational vision}

'When we accept that the objective of higher education is to prepare students for the society in which they have to function, education must go far beyond transfer of knowledge.' (Dochy, 2005)

In Belgium quality in higher education is more and more expressed in terms of competences of the graduates. This is due to developments in society and a changing approach of learning. The ultimate goal of higher education must be that students are able to guide themselves. Pressure also comes from economics. The labour market increasingly needs employees who can take initiative, who are able to think critically, who have a sense of responsibility and who are flexible. That is why there is a paradigm shift in higher education.

The constructivist paradigm sees learning as an active, cumulative and constructive process. Meaningful learning is linked to the context. It happens in a social context, in interaction with others. This kind of learning requires acting in realistic situations. The lecturer is the one who has to create powerful learning environments. The lecturer has to guide students to a higher level of functioning. The students on the other hand create and re-create meaning through experience. The students can form new meaning when they are able to relate old and new experiences. The consequence of all this is that higher education has to enhance a student-centred vision on learning and teaching. To realize these objectives, some conditions are:

- Competence based higher education emphasizes the importance of competences in the construction of a curriculum, in the selection of the course materials and the evaluation of the students. Is also encompasses tasks a graduate has to perform and real situations in which a graduate must be able to act.

- Students are confronted with problems and situations that stimulate them to acquire knowledge, attitudes and abilities that are necessary to resolve problems. Study tasks are organized in a way that students learn to work and think autonomously, often in a team with others.

- In evaluations students have to demonstrate that they are able to solve realistic problems from practice. Alternative evaluation methods are therefore necessary. Examples are self-assessment, peer assessment, $360^{\circ}$ feedback and multiple evaluations.

Elements of a competence based educational vision are:

- The educational vision is well described;

- The educational vision is guiding the education;

- The educational vision respects the individuality of each student;

- The educational vision invites lecturers to work with authentic learning situations such as cases, projects, etc;

- The educational vision integrates research and education;

- The educational vision is broadly accepted by lecturers, students and other stakeholders.

\subsection{A competence based profile}

An educational profile describes the starting qualifications that are necessary to acquire the competences required. When organizing degree programmes you must develop an 
educational profile that matches the specific situation. Developing a profile dialogue with the professional field is necessary. On the basis of discussions with the field the most important result area of the profession, the function or the role must be described. Meaningful is the 'wisdom of practice' method which stimulates an active dialogue between the professional field and the higher education institutes. It should result in the description of what the professional field considers the most important competences. Another method consist in describing the context of the profession, the activities, the roles and responsibilities of the profession, the typical professional attitude, relevant trends, etc. This should be done in consideration with the professional field

Descriptions of competences in an educational profile are not long lists of behaviour, but rather stories about the context in which the competences become meaningful for the field.

Elements of such a profile are:

- The education profile expresses a clear view of meaningful situations in the professional field.

- The education profile describes the competences a young professional has to master.

- The education profile is the framework to develop the curriculum and the courses.

- The education profile is the way a degree programme expresses its uniqueness.

- There is strong link between the education profile and the professional profile.

- All colleagues have been consulted before the education profile is described.

- The education profile has been discussed with all stakeholders.

- The education profile stimulates lecturers and students to explore new situations in the professional field.

\subsection{A competence based curriculum}

A curriculum is not developed out of a vacuum, it is not static. Some points are crucial for the development of a competence based curriculum.

- Such a curriculum has clear development lines that are structured around professional situations and core competences;

- Such a curriculum gives space to individual learning tracks, differentiated according to the progress of the student;

- A growing integration of knowledge, attitudes and capabilities;

- A strong relation with the practice of the profession; all objectives and activities are related to the profession;

- Learning takes place in meaningful situations that represent the situations in which the students have to apply their competences.

Elements of such a competence based curriculum are:

- The educational vision is the starting point of the development of the curriculum.

- Every course is justified within the frame of lines of development and progress and competences.

- The development of the curriculum and the evaluation methods are intertwined.

- Lines of development support students to make their individual learning tracks.

- Lines of development are developed in the curriculum in a coherent way.

- Lecturers and students have a say in the development of the curriculum.

- The curriculum stimulates the exploration of the professional field. 


\subsection{A competence based learning environment}

Lecturers change and adjust their courses with much enthusiasm year after year. They rely on their experiences with what works in the classroom and what does not. Often they work, unwittingly, in a competence based way. A method to develop a strong learning environment starts with discovering the typical characteristics of adequate learning. We define a strong learning environment as 'situations and contexts that elicit the necessary learning processes and that stimulate and maintain the motivation to reach meaningful learning results amongst students' (Decorte, 1996). To us the method of appreciative inquiry is very suitable to motivate lectures to co-operate when developing a strong learning environment. We will describe this method more in detail in the last section.

The next step is the dreaming phase: imagining a new future with a real competence based degree programme in ten years time for instance.

The third step is elaborating materials that result from the previous two stages. This should result in very detailed propositions and actions. It could lead to a list of criteria that are used to check whether a degree programme is effectively competence based. The last step consists in elaborating action plans and courses.

We learned that a successful implementation of a competence based curriculum is more than a pure pedagogical experiment. Critical success factors are personnel policy, the organizational context and the relationships with stakeholders, such as the professional field.

Criteria to evaluate the degree to which the learning environment is competence based, are:

- The choice of the learning environment is determined by characteristic situations from the professional field.

- There is a balance between control by the lecturer and control by the student.

- The evaluation by the students is the starting point for the development of courses.

- Teaching and learning activities are rich and differentiated.

- Students can bring in their experiences from the professional field.

- Authentic situations are an essential part of the learning environment.

- The educational process and the evaluation are congruent.

- The professional field is integrated in the learning environment.

- The learning environment stimulates the exploration of the professional field.

\subsection{Relationships with the professional field}

The core competences of a degree programme must be discussed with the professional field. In some countries it is the professional field that is responsible for prescribing the competences of the profession, in other countries the higher education institute develops the competences which are later discussed with the professional field. In Flanders we are obliged to integrate the professional field in the discussion and the development of the competences. In the reference frame of the accreditation board the institute has to provide evidence for the alignment of its objectives with the requirements set by colleagues and with the needs and desires of the intended professional field.

Elements of a good relational practice with the professional field are:

- Structural moments of consultation with the professional field;

- The education has a policy of networking with the professional field;

- The professional is involved in the process of educational development; 
- Representatives of the professional field participate in educational activities such as lectures, seminars, evaluation of thesis, etc;

- The institute has a permanent dialogue with the professional field and has a culture of co-operation.

\subsection{A competence based personnel policy}

Since institutes of higher education are continuously subject to change, the workload of their lecturers increases year by year. Lecturers have to combine more roles. The old systems of personnel management seem to become inadequate and to get stuck. There is a need for a new personnel management system that supports lecturers in competence based education. This new orientation is often experienced as threatening for lecturers. They have to cope with uncertainty and they must adapt to new roles.

Elements of a competence based personnel policy are:

- Lecturers professionalize systematically to develop the required competences.

- The personal development plan of the lecturers is an instrument in the development of their competences.

- Tasks are assigned according to the competences of the personnel.

- Lecturers get opportunities to develop their competences.

- Lecturers are coached and supported in using their competences in competence based education.

- New tasks are seen as opportunities to develop new competences.

\subsection{An organization that supports competence based education}

Institutes of higher education that change in the direction of competence based models often have to face problems that are related to the structure and the culture of their organizations. After all, competence based education presupposes a lot of flexibility and co-operation on the side of the lecturers. Creativity and innovation are also needed. Those demands are often difficult to combine with existing structures and procedures.

Elements of an organization that supports a competence based orientation are:

- The organization has clear channels for internal communication.

- The central services of the organization too support the competence based way of working.

- The organizational structures and the culture allow and stimulate creativity and dynamism.

- Teams employ the plan-do-check-act methodology.

- Teams reflect on their actions.

\subsection{The coaching of the students}

In competence based education the coaching of the students becomes the critical success factor.

Institutes of higher education are confronted with a changing student population. New target groups of students enter. They require a new approach and more flexibility. More and more students need individual study tracks.

This has implications for competence based education: 
- The vision on what competence based education should be is the basis of the policy concerning how students enter, move up in and exit their programmes.

- The organization has procedures to assess previously acquired competences.

- The coaching of students individual study tracks takes account of what is necessary for the development of the student's competences.

- The coaches function as care coordinators of the students.

- The coaching of the study tracks is based on a good co-operation between lecturers, administrative staff and experts.

- The coaching of the study tracks of the students is mainly based on is the self responsibility of their learning processes.

\section{IMPLEMENTATION}

The subsequent implementation of a competence based approach often causes resistance in the organization. This resistance is an important sign management cannot ignore. The challenge is to work with this resistance and not to deny it. In trying to understand the meaning of this management explores the feelings of colleagues, understands their fears and also gets insight in those aspects of the innovation process that are not fully developed or well prepared yet. So, attention for resistance is critical. Let us shed some light on some of these factors.

- Tension can arise because the emphasis is on the products and not on the process. That can cause means-goal confusion. That is the case when the competence orientation is realized in an instrumental way or, for instance, when the government controls the competence basis of education. Indicators, matrices, concordance tables and so on get more attention as a means to prove evidence, than the process that is supported by all lecturers. You often see that the emphasis on those formal products takes away the energy of people to be engaged in the innovation process.

- A second problem is the orientation of the change process. Are the changes imposed top-down or also suggested bottom-up? We have the impression that institutes that enthusiastically develop competence based education emphasize the power of the energy of their colleagues and that they are less directive. They promote and leave space for processes.

In our approach we focus on the process dimension; the instrument we developed had to foster the competence orientation of the institutes more than products, while the products are not unimportant, of course. Therefore we try to stimulate the development of so-called 'relational practices'. Those are the relations and good practices that people build up together. We use the appreciative inquiry (AI) approach. That approach emphasizes the strengths of people and their organizations much more than the problems and the weaknesses. We learned that the traditional problem solving approach, that is so commonly used in organizations today, often takes away a lot of energy and does not result in an actual change process. The AI approach on the other hand gives people energy.

It takes us too far to elaborate on $\mathrm{AI}$ in depth. We will only briefly describe a step plan of the appreciative inquiry process. It is a method- in fact also a way of being and thinkingto discover and to appreciate those things that already work very well in the organization and to build up a common future for the organization.

Let us first compare the traditional problem solving approach with the appreciative inquiry approach. 


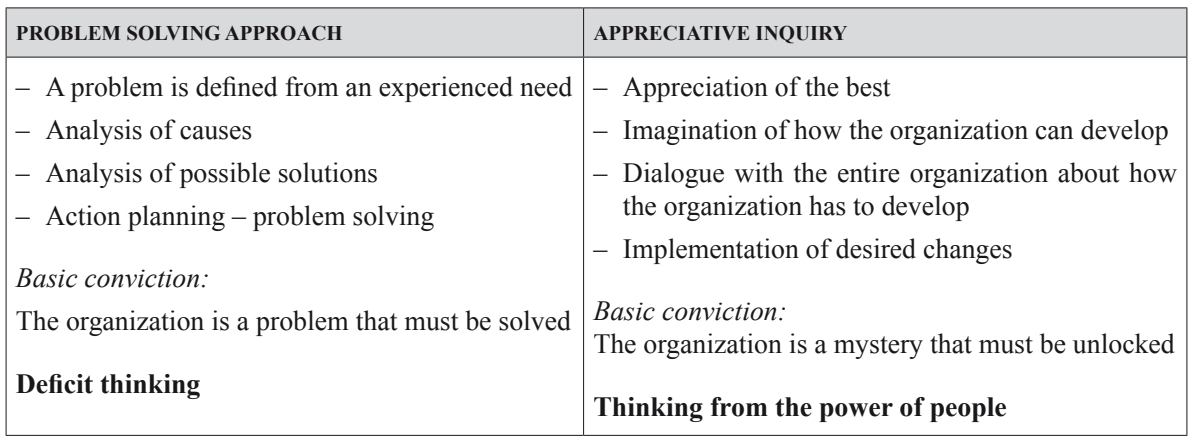

FIGURE 6: Comparison of the problem solving approach with appreciative inquiry

Cooperrider (2003) describes four phases to realize innovation in an organization.

\section{- Phase 1: Discovery}

In this phase we try to detect what works well concerning the subject we want to develop. Lecturers are asked to tell the stories of their good practices. The next step is to explain what in those stories gives them energy, what are the factors that are critical for success. The result is a list of good practices and designs that give energy and insight in what determines whether a course stimulates and fosters the learning process. Those factors can be used by others to design their own courses.

These are the things people are proud of. The questions are crucial:

'Tell me a story about a moment or a situation when you were proud as a teacher, because you could support the student in becoming more competent, a moment or event or phase when you could see your students grow in the direction of a competent professional.

'Looking back on this story, tell me what you did, what the student did, what the factors in the environment were that fostered the development of the student. What factor can we find that made learning possible, that stimulated the growth process of young people?'

By answering these questions we learn what works in educational processes and when a competence based orientation leads to real learning.

- Phase 2: Imagining a future

The next step is the dreaming phase: the imagination of a new future in ten years time for instance and imagining a real competence based degree programme.

In this second phase we ask you to dream about your future. You know from the previous phase what works and what learning is. Try to imagine what competence based learning can mean for you as a lecturer in the future. What are the ideal images of competence based education to you?

- Phase 3 Design

The third step is the elaboration of materials that resulted from the previous two stages. This should result in very detailed propositions and actions. This could for instance lead to a list of criteria that are used to check whether a course is actually competence based. In this step we must 'anchor', i.e. translate what could work into what we want to realize now. We design the future we want. 


\section{- Phase 4 Realization}

The last step is elaborating on action plans and courses. This is the phase of learning, adapting, improvising and trying out. The potential to come to real innovation is very high in this phase, because there is a shared view on the future that challenges everybody to co-operate. It is important to develop 'an appreciative eye', i.e. learning to see the positive side of systems, procedures, structures etc. It is often meaningful to use 'new words' to describe the proper reality, because 'words create worlds'.

We have to define the actions, goals, the space of time and the means that are necessary to realize the image of the future.

\section{CONSEQUENCES}

What can be the added value of competence based education? And under what circumstances can it be realized?

In the first place the added value of competence based education is that the students are better prepared than in a traditional education to function in the professional field. Often we hear the objection that in competence based education the significance of knowledge diminishes. We must stress, however, that knowledge will be more integrated and is anchored more.

Secondly this approach seems to be much more motivating for the students because they are confronted from the start with realistic and authentic professional situations: cases, exercises, projects, visits. The evaluation processes too must be congruent with the competence orientation. They must also at least rely on authentic situations. Ideally competences are tested in realistic situations. Assessment is a much deeper and more intense form of evaluation than purely theoretical written evaluation. The early contact with the professional field results in a better understanding of 'the soul of the profession'.

For the lecturers the competence based way of working is indeed more challenging. To keep their courses up-to-date and their course contents relevant they are obliged to stay touch with the professional field on a regular basis. Nevertheless, the resistance of lecturers for this orientation often hinders real commitment. That is why we plead for a positive and motivating approach such as the appreciative inquiry approach which was described in the previous section.

Of course the shift to competence based education requires that some contextual conditions are fulfilled.

The first condition is time. The shift is a process that takes time, a lot of preparation, testing and adjusting. The higher education institute must be prepared to invest in time, energy and people.

Next, the culture of the organization must be open enough for the new approach. When people are afraid of change, when they focus on their status of autonomous professionals, when they are not used to co-operating and do not trust each other or management, then it will be necessary first to work on these organizational problems.

It is also necessary that the students are seen as important stakeholders who can be involved in the discussions. Furthermore, the institute also has to involve external stakeholders, such as representatives from the professional field, in the debate about the competences. This requires a rather democratic orientation of the organization. In the end, it will be the professional field that will evaluate the competences of the graduates. 


\section{SOURCES}

COOPERRIDER, D., WHITNEY, D; \& STAVROS, J. (2003): Appreciative Inquiry Handbook. Berrett-Koehler.

DOCHY, RF. \& NICKMANS, G. (2005): Competentiegericht opleiden en toetsen. Utrecht, Lemma.

DECORTE, E. (1996): Actief leren binnen krachtige leeromgevingen. Impuls, jrg. 26, 4,p.145-146.

INTERNATIONAL FEDERATION OF SOCIAL WORKERS (2000): International definition of Social Work. http://www.ifsw.org/

MINNE, E. (2008): Inspiratiegids voor een competentiegerichte opleiding. Antwerpen, Garant.

'The social work profession promotes social change, problem solving in human relationships and the empowerment and liberation of people to enhance wellbeing. Utilising theories of human behavior and social systems, social work intervenes at the point where people interact with their environments. Principles of human right and social justice are fundamental to social work"; http://www.ifsw.org. 